\title{
Mechanism of Choline-induced Secretion of Catecholamines from the Cat Adrenal Medulla: Involvement of Nicotinic Receptor
}

\author{
Masaru SORIMACHI and Shigeto NiSHIMURA \\ Department of Physiology, Kagoshima University, School of Medicine, \\ Kagoshima, 890 Japan
}

\begin{abstract}
Cat adrenal glands were retrogradely perfused in vitro with modified Locke's medium and the mechanism of catecholamine (CA) secretion induced by choline was investigated. Choline-induced secretion of CA was accompanied by release of dopamine- $\beta$-hydroxylase, but not by that of phenylethanolamine- $N$-methyl transferase, indicating that an exocytotic mechanism is involved in the secretion. Choline failed to induce the secretion of $\mathrm{CA}$ when $\mathrm{Ca}$ was absent from the perfusion solution. On the other hand, secretion increased when the concentration of $\mathrm{Ca}^{2+}$ in the perfusion medium was raised to $10 \mathrm{~mm}$. Stimulation of secretion by choline was observed from a concentration of $1 \mathrm{~mm}$, and half-maximal secretion occurred at about $10 \mathrm{~mm}$. The stimulatory action was weaker than that of acetylcholine(ACh); the effect of $100 \mathrm{~mm}$ chloine was approximately equal to that of $0.02 \mathrm{~mm}$ ACh. Secretion induced by a low concentration of choline was abolished by a nicotinic blocker, hexamethonium, while the response to choline at a concentration higher than $130 \mathrm{~mm}$ was only partially inhibited by cholinergic antagonists. The effects of choline and a low concentration of ACh were additive. On the other hand, $100 \mathrm{~mm}$ choline inhibited the response to a supramaximal concentration of $\mathrm{ACh}(0.5 \mathrm{~mm})$, suggesting that $\mathrm{ACh}$ and choline stimulate the same nicotinic receptor. It is concluded that choline acts partially as a nicotinic agonist and that a concentration higher than 130 $\mathrm{mm}$ causes secretion by a mechanism additional to nicotinic receptor activation.
\end{abstract}

Key Words: adrenal medulla, catecholamines, calcium choline, dopamine- $\beta$-hydroxylase.

We previously demonstrated that, in perfused rabbit adrenal glands, replacement of $\mathrm{NaCl}$ in the perfusion solution by equimolar choline chloride caused an immediate secretion of adrenaline. This secretory response could be ascribed to choline, however, the secretory effect of choline was much weaker than that

Received for publication December 10, 1981

反町 勝, 西村茂人 
of acetylcholine (ACh) (Sorimachi, 1968). LASTOWECKA and Trifaro (1974) also reported a similar finding for perfused bovine adrenal gland. Since replacement of $\mathrm{NaCl}$ by sucrose also induced the exocytotic secretion of catecholamines (CA), they ascribed this secretion to unknown mechanisms directly associated with $\mathrm{Na}^{+}$deprivation. However, they did not determine whether or not the secretory response observed in a choline-substituted medium could be inhibited by cholinergic antagonists.

We therefore carried out experiments to determine whether the secretory effect of choline can be ascribed to the interaction of choline with ACh receptors or to some other effect of $\mathrm{Na}^{+}$removal. The results indicate that choline is a partial nicotinic agonist, but that secretion caused by a high concentration of choline in the presence of cholinergic antagonists involves a mechanism other than nicotinic receptor activation. A preliminary account of this study has been presented at a local meeting of the Physiological Society of Japan held at Kyushu University (October 9, 1981).

\section{MATERIALS AND METHODS}

Adrenal glands of both sides of the cat were isolated and perfused at room temperature $\left(25-30^{\circ} \mathrm{C}\right)$ in the reverse direction through the adrenolumbar vein using a procedure developed by Douglas and Rubin (1961). A flow rate of 1.0 $\mathrm{ml} / \mathrm{min}$ was kept constant by means of a peristaltic pump. Samples of perfusate were usually collected in test tubes containing acetic acid. When dopamine- $\beta$ hydroxylase activity (DBH) was measured, non-acidified samples were divided into two parts; one for DBH assay was transferred to test tubes containing bovine serum albumin (final $0.25 \%$ ) and the other for CA assay to test tubes containing acetic acid. Modified Locke solution of the following composition was used (mM); $\mathrm{NaCl}, 150 ; \mathrm{KCl}, 5 ; \mathrm{CaCl}_{2}, 2 ; \mathrm{MgCl}_{2}, 1$; Tris/HCl ( $\mathrm{pH} \mathrm{7.0-7.3),} \mathrm{5;} \mathrm{glucose,}$ 5.5. When the concentration of choline chloride or $\mathrm{CaCl}_{2}$ was increased, an osmotically equivalent amount of $\mathrm{NaCl}$ was omitted.

$\mathrm{CA}$ in the effluents was determined by use of the conventional fluorimetric method (ANTON and SAYRE, 1962). Effluents were assayed without purification on alumina, although inclusion of this step did not alter the results. Differential determination of adrenaline and noradrenaline was carried out based on the differential oxidation of the two amines at $\mathrm{pH} 7.0$ and $\mathrm{pH} 3.5$. $\mathrm{DBH}$ and phenylethanolamine- $N$-methyl transferase (PNMT) activities in the effluents were measured radiochemically using the method of MoLINOFF et al. (1971) as described previously (SORIMACHI and YoSHIDA, 1979) and by the method of SAAVEDRA et al. (1974), respectively.

\section{RESULTS}

Exocytotic nature of $C A$ secretion caused by choline

When a control perfusion solution was switched to a solution containing 
A

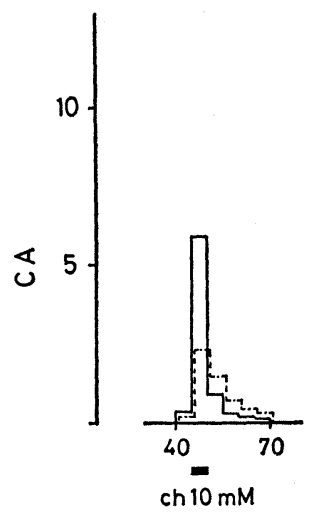

B

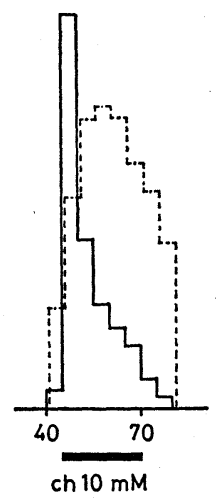

C

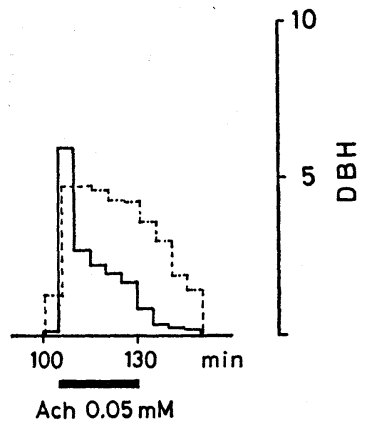

Fig. 1. Secretion of CA and DBH from the perfused adrenal gland of the cat caused by $10 \mathrm{~mm}$ choline or $0.05 \mathrm{~mm} \mathrm{ACh}$. The heights of the columns represent the amount of $\mathrm{CA}\left(\mu \mathrm{g}\right.$, continuous line) and DBH (nmol/phenylethanolamine formed $/ \mathrm{hr}$ at $37^{\circ} \mathrm{C}$, dashed line) in the effluents collected every 5 min. Heavy lines under the graphs represent the periods of stimulation by choline or ACh.

$10 \mathrm{~mm}$ choline- $\mathrm{Cl}$ for a short period of time, e.g., $5 \mathrm{~min}$, the rate of CA secretion increased immediately and returned to the prestimulation level within $10 \mathrm{~min}$ (Fig. 1A). When the gland was perfused with $10 \mathrm{~mm}$ choline for a longer period, the increased rate of secretion was not maintained at a constant level but lowered with time; the rate of secretion 30 min after the onset of stimulation declined to a level nearly the same as or a slightly higher than the initial level (Fig. 1B). This secretion pattern was quite similar to that seen in the case of ACh stimulation (Fig. 1C). The time-dependent decline of secretion during continuous stimulation by $\mathrm{ACh}$ has been explained by desensitization of the nicotinic receptors (KIRPEKAR and Prat, 1978).

Secretion of CA was always accompanied by the release of $\mathrm{DBH}$, but not by that of PNMT, a cytoplasmic enzyme, suggesting the exocytotic nature of the secretion. The secretion of DBH lasted for a longer period than that of CA even in the case of a shorter period of stimulation, as has often been demonstrated in the perfusion experiments (Fig. 1A; LASTOWECKA and TrIfaro, 1974; SORIMACHI and Yoshida, 1979; ITo et al., 1980). This tendency was more pronounced with stimulation for a longer period (Fig. 1B). Since the simultaneous secretion of $\mathrm{CA}$ and $\mathrm{DBH}$ in response to $\mathrm{ACh}$ was observed in isolated chromaffin cells (FENwICK et al., 1978), the long-lasting release of DBH seen in the present preparations may be due to the existence of vascular barriers for high molecular weight proteins.

The effect of external Ca concentration on $C A$ secretion caused by choline

In the absence of external $\mathrm{Ca}$, the secretory response to $10 \mathrm{~mm}$ choline was 

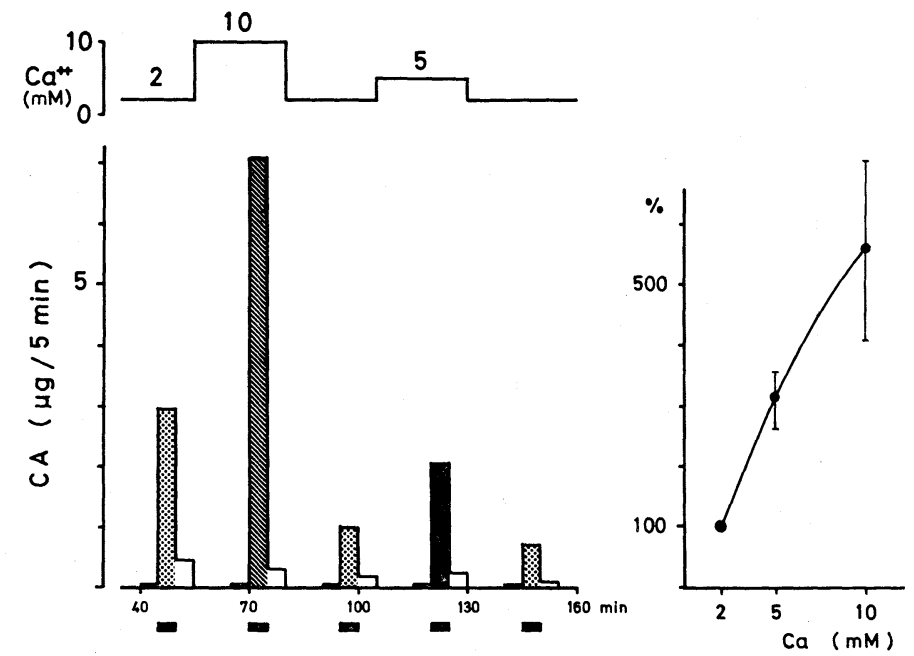

Fig. 2. The potentiating effect of a higher concentration of $\mathrm{Ca}$ on $\mathrm{CA}$ secretion induced by $20 \mathrm{~mm}$ choline $\mathrm{Cl}$. Left panel: a representative experiment is shown, in which an adrenal gland was perfused for 15 -min periods with a medium containing $\mathrm{Ca}$ of $2 \mathrm{~mm}$ or higher before 5-min stimulation with choline (the filled rectangles under the figure). Right panel: relationship between choline-induced $\mathrm{CA}$ secretion and $\mathrm{Ca}$ concentration. The results were expressed as $\%$ of the mean of the preceding and the following responses for $2 \mathrm{~mm} \mathrm{Ca}$. Points and vertical bars represent the mean and S.E.M., respectively $(N=4)$.

negligibly small $(N=3)$. There was a quantitative relation between the amount of CA secreted by 10-20 mm choline and the concentration of $\mathrm{Ca}$ in the medium. This was shown by experiments in which responses to choline were tested alternately in a solution containing $2 \mathrm{~mm} \mathrm{Ca}$ and in a solution containing a higher concentration $\mathrm{Ca}$ (Fig. 2, left panel). The magnitude of the response under a given concentration of $\mathrm{Ca}$ was expressed as a percentage of the mean of the preceding and the following ones in the presence of $2 \mathrm{~mm} \mathrm{Ca}$, and the results are summarized in the right panel of Fig. 2. CA secretion caused by choline increased as the concentration of $\mathrm{Ca}$ was raised. Also, CA secretion caused by $\mathrm{ACh}$ was reported to be dependent on the concentration of Ca (Douglas and RUBIN, 1963).

The effects of various concentrations of choline on CA secretion

Choline stimulation of CA secretion was observed from a concentration of $1 \mathrm{~mm}$. In order to see the dose-response relation, the responses to choline at various concentrations were tested. The responses to choline at $10 \mathrm{~mm}$ and at another concentration were observed alternately and the observed response was expressed as a percentage of the mean of the preceding and the following responses to $10 \mathrm{~mm}$ choline. As shown in Fig. 3, the response was dependent on the concentration of choline. However, the responses to $150 \mathrm{~mm}$ choline were much larger than those expected from the dose-response curve obtained at concentrations 


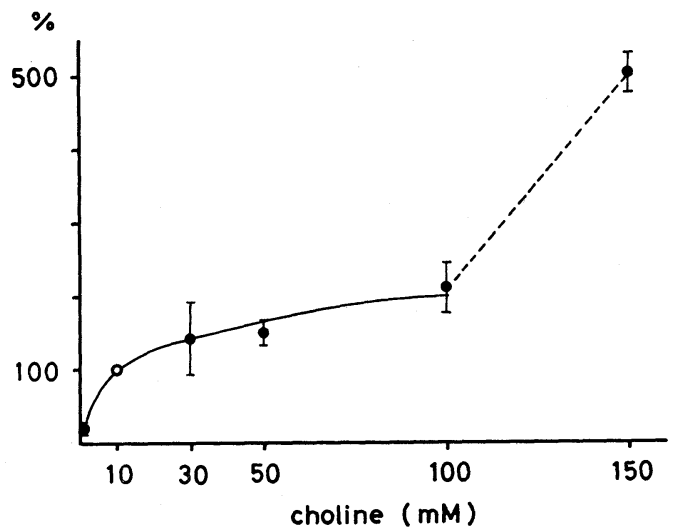

Fig. 3. The effects of different concentrations of choline on CA secretion. An adrenal gland was stimulated for a 5-min period with a medium containing choline of $10 \mathrm{~mm}$ or another concentration alternately every $20 \mathrm{~min}$, and the responses were compared to the mean of the preceding and the following ones to $10 \mathrm{~mm}$ choline. Points and bars represent the mean and S.E.M., respectively $(N=3-4)$.

lower than $100 \mathrm{~mm}$. This suggests that CA secretion caused by a high concentration of choline involves a mechanism additional to that by a low concentration of choline.

The choline-induced CA secretion in the range of choline concentration from 0 to $100 \mathrm{~mm}$ was significantly lower than that induced by the optimal concentration of ACh. For example, the responses to $0.01,0.02$, and $0.05 \mathrm{~mm} \mathrm{ACh}$ are $55 \pm 5 \%$ (mean \pm S.E.M., $N=3), 95 \pm 12 \%(N=3)$, and $178 \pm 26 \%(N=3)$ of the mean of the preceding and the following responses to $100 \mathrm{~mm}$ choline, respectively. Thus, the stimulatory effect of $100 \mathrm{~mm}$ choline is equivalent to that of $0.02 \mathrm{~mm}$ ACh. These results raise the serious question for the possibility that the secretion caused by choline is due to ACh contaminating the choline reagent. This could, however, be ruled out by the finding that alkaline treatment $(\mathrm{pH} \mathrm{10.5,60} \mathrm{min)}$ of choline reagent, which destroys the ester bond of $\mathrm{ACh}$, did not inhibit the response to choline (Fig. 4).

The effects of anti-cholinergic agents on $C A$ secretion caused by choline

The secretory effect of $10 \mathrm{~mm}$ choline was almost completely abolished by a nicotinic blocker, hexamethonium $\left(1.8 \mathrm{~mm}, \mathrm{C}_{6}\right)$ (Fig. 5). A higher concentration of atropine $(0.1 \mathrm{~mm})$ also inhibited the response to choline, but a lower concentration $(1.4 \mu \mathrm{M})$ sufficient to block muscarinic receptors inhibited the cholineinduced secretion only partially $(25 \pm 4 \%, N=3)$. Since atropine is capable of blocking nicotinic receptors as well (YosHIZAKI, 1973; TSUJIMOTO and NisHIKAWA, 1975; TrIFARO and LEE, 1980), the role of muscarinic receptors in this secretion is obscure. Secretion caused by a low concentration of choline obviously involves $\mathrm{C}_{6}$-sensitive receptors, most probably nicotinic $\mathrm{ACh}$ receptors. These results, 


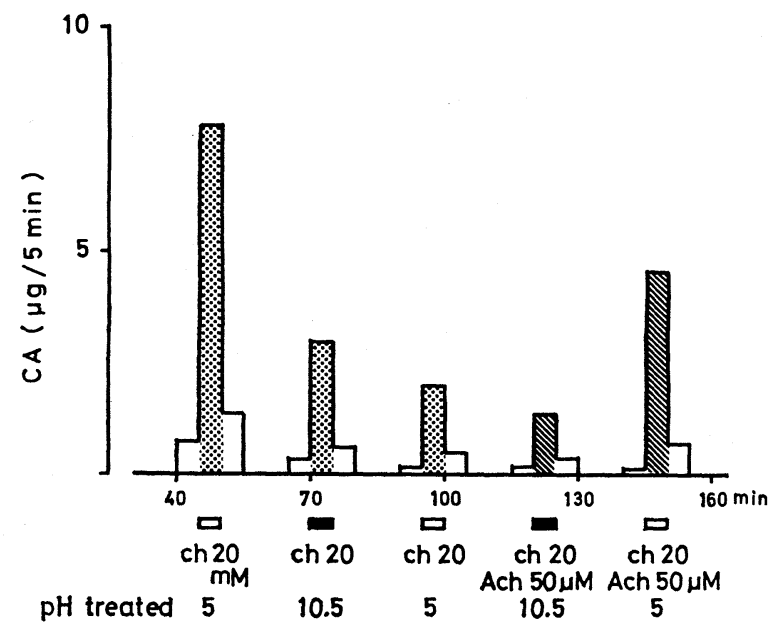

Fig. 4. Effect of choline or choline plus ACh at alkaline pH on CA secretion. A solution of choline $\mathrm{Cl}$ dissolved in distilled water was divided into two parts: one was adjusted to $\mathrm{pH}$ 10.5 by adding a small amount of $1 \mathrm{~N} \mathrm{NaOH}$ and the other was left at about $\mathrm{pH} 5$. Each solution was further divided into two parts. Each half was given ACh and left for $60 \mathrm{~min}$ at room temperature. The required ions and buffer were added to these solutions before starting the experiment. Note that only the response to ACh was abolished after alkaline treatment.
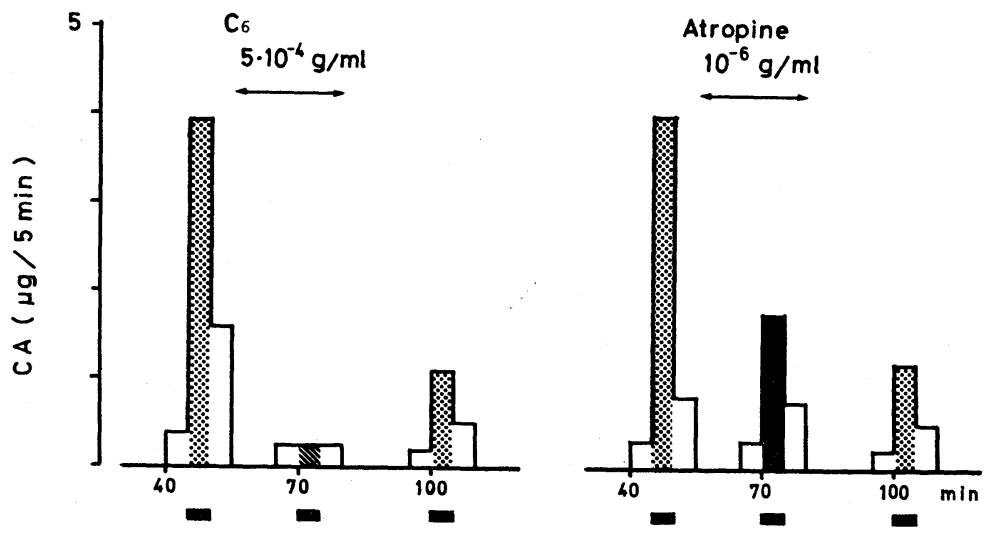

Fig. 5. The effect of hexamethonium or atropine on CA secretion induced by $10 \mathrm{~mm}$ choline. The adrenal was treated with an agent for $15 \mathrm{~min}$ before 5-min stimulation.

together with the weak stimulatory effect of choline, raise two possibilities. One is that choline stimulates the secretomotor nerve terminals to induce ACh secretion. The other is that choline acts as a partial nicotinic agonist because of the lack of the acetyl group. These alternatives will be differentiated by the antagonistic effect of a high concentration of choline on ACh response (see below). 
When the adrenals were stimulated with the highest concentration of choline $(150 \mathrm{mM})$ in the presence of $\mathrm{C}_{6}(1.8 \mathrm{mM})$ and atropine $(0.1 \mathrm{mM})$, the responses were never abolished, although they were markedly reduced $(37 \pm 12 \%$ of those in their absence, $N=5$ ). Two possibilities for this partial inhibition could be considered. Firstly, the concentration of agents employed are below the blocking doses as compared to the concentration of choline so that $\mathrm{ACh}$ receptors are only partially blocked. Secondly, cholinergic antagonist-resistant secretion is due to $\mathrm{Na}^{+}$ deprivation as described earlier. In order to differentiate the two alternatives, we tested the effects of various concentrations of choline in the presence of cholinergic antagonists. These agents completely inhibited the response to a concentration of choline lower than $120 \mathrm{~mm}$, but a significant increase of secretion was observed at a concentration higher than $130 \mathrm{~mm}$ (Fig. 6). If cholinergic antagonist-resistant secretion is related to $\mathrm{Na}^{+}$deficiency, replacement of $20 \mathrm{~mm}$ $\mathrm{NaCl}$ by sucrose $(40 \mathrm{~mm})$ in the presence of $130 \mathrm{~mm}$ choline should evoke more secretion. The result clearly shows that this was the case (Fig. 6, right panel). This was also confirmed by the fact that the responses to $150 \mathrm{~mm}$ choline were comparable to those to choline $(130 \mathrm{~mm})$ containing $40 \mathrm{~mm}$ sucrose. Consistent with this view, patterns of secretion of individual amines are different under two conditions; noradrenaline is predominantly secreted in response to $150 \mathrm{~mm}$ choline, but two amines are nearly equally secreted at $10 \mathrm{~mm}$ choline. The ratio of adrenaline to total CA is $31 \pm 4 \%(N=5)$ in response to $150 \mathrm{~mm}$ choline, the values being significantly smaller than that observed at $10 \mathrm{~mm}$ choline $(62 \pm 3 \%, N=14)$.
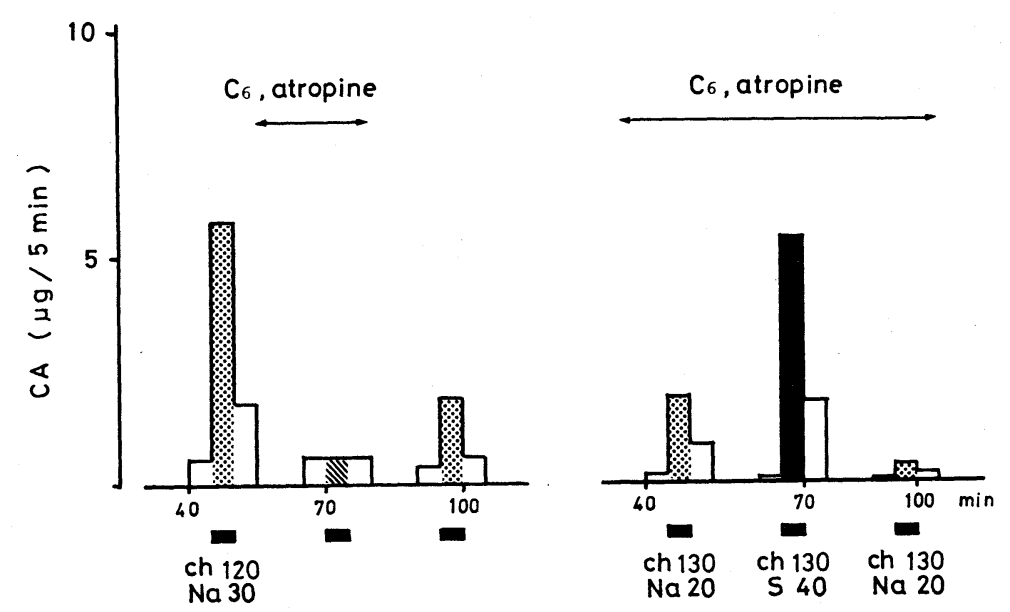

Fig. 6. The effect of hexamethonium and atropine on CA secretion induced by a high concentration of choline. The left figure shows the complete inhibition of the response to $120 \mathrm{~mm}$ choline by cholinergic antagonists. The right figure shows that the response to $130 \mathrm{~mm}$ choline persists in the presence of cholinergic antagonists and this was potentiated by replacement of $20 \mathrm{~mm} \mathrm{NaCl}$ with an isotonic concentration of sucrose (S). 


\section{The effect of choline on ACh-induced secretion}

If the secretion caused by a low concentration of choline is due to a stimulatory effect on cholinergic nerve terminals, the effects of the submaximal concentration of ACh and choline should be additive, but this should not be the case when the concentration of ACh is supramaximal.

The responses to 10 or $100 \mathrm{~mm}$ choline added to $0.02 \mathrm{~mm}$ ACh were increased to $164 \pm 9 \%(N=5)$ or $183 \pm 15 \%(N=5)$ of those to ACh alone, respectively (Fig. 7 , left panel). This potentiation by choline is not caused by $\mathrm{Na}^{+}$deficiency of the choline-containing medium, since secretion by $\mathrm{Na}^{+}$reduction is valid only when the concentration of $\mathrm{Na}^{+}$is lowered below, at least, $30 \mathrm{~mm}$ (Fig. 6).

On the other hand, the addition of $100 \mathrm{~mm}$ choline over and above the supramaximal concentration of ACh $(0.5 \mathrm{~mm})$ induced less CA secretion than ACh alone; the responses to $\mathrm{ACh}$ plus choline were reduced to $60 \pm 10 \%(N=4)$ of those to ACh alone (Fig. 7, right panel). Choline at $10 \mathrm{~mm}$ did not inhibit the responses to ACh significantly $(96 \pm 8 \%$ of the controls, $N=5)$. Since CA secretion does not show any tendency to decline at a higher concentration of ACh (SORIMACHI, 1968; Hochman and Perlman, 1976; Holz and Senter, 1981), these results could be best explained if one considers that $\mathrm{ACh}$ and choline compete for the same nicotinic ACh receptors. Since the concentration of choline producing $50 \%$ of the maximal secretion is much higher (approx. $10 \mathrm{~mm}$ according to Fig. 4) than that to ACh (0.005-0.02 mM depending on the experiments, SCHNEIDER et al., 1977; IsHIKAWA et al., 1977; FENWICK et al., 1978; KIDOKORO and RITCHIE, 1980; KILPATRICK et al., 1980), only the higher concentration of choline would possess the capacity to replace ACh on fully saturated receptor, and thus total CA secretion would be reduced because of the weak secretory activity of choline. This view is not incompatible with the observation that choline and $0.02 \mathrm{~mm} \mathrm{ACh}$

A

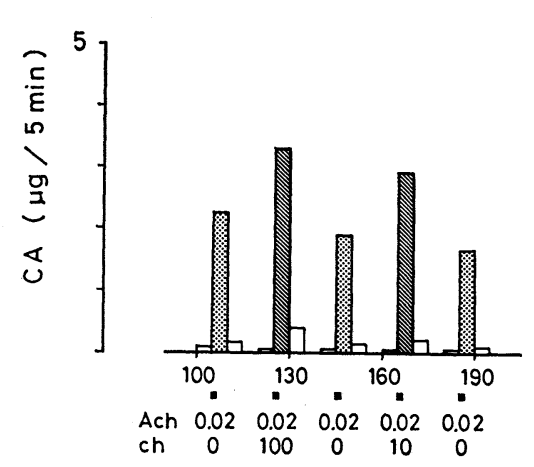

B

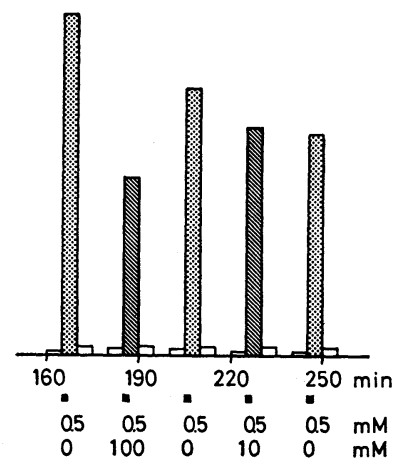

Fig. 7. The effect of choline on the responses to the submaximal concentration $(0.02 \mathrm{~mm}$, left) and the supramaximal concentration $(0.5 \mathrm{~mm}$, right) of ACh. An adrenal gland was stimulated for a 2-min period with a medium containing $\mathrm{ACh}$ in the absence or presence of choline (10 or $100 \mathrm{mM}$ ) alternately. 
are synergistic in increasing secretion, since receptors are not saturated with such a low concentration of ACh and the secretory activity of $10-100 \mathrm{~mm}$ choline is comparable to that of 0.01-0.02 mM ACh.

\section{DISCUSSION}

The results of the present study show that choline stimulates nicotinic receptors on the adrenomedullary cells and induces $\mathrm{CA}$ secretion as $\mathrm{ACh}$, a physiological transmitter, does. This secretion is not caused by ACh contaminating the choline reagent. Since a high concentration of choline inhibits the maximal response to $\mathrm{ACh}$, it is also unlikely that $\mathrm{ACh}$ either released from the secretomotor nerve terminals by choline or synthesized in these terminals from choline is responsible for this secretory response.

The results suggest that the nicotinic receptors have binding sites for choline. However, the affinity of choline for these receptors is $500-1,000$ times lower than that for $\mathrm{ACh}$, as was reflected by the differences in the concentrations producing $50 \%$ of the maximal secretion. As the apparent maximal response to choline is smaller than that to $\mathrm{ACh}$, simultaneous bindings of the acetyl group and choline to receptors may be essential for full activation.

During the preparation of this manuscript, a paper by HoLz and SENTER (1981) has appeared, in which they have also shown the stimulatory effect of choline on CA secretion from bovine chromaffin cells maintained in culture. Our results are in good agreement with theirs with respect to the requirement of $\mathrm{Ca}^{2+}$, the minimal effective concentration of choline and the sensitivity to nicotinic blocker. However, some differences were noticed. We observed the synergistic effects of choline and submaximal concentration of $\mathrm{ACh}(0.02 \mathrm{~mm})$, while they reported that, under similar experimental conditions, choline at a concentration higher than $1 \mathrm{~mm}$ inhibited the submaximal response to $0.03 \mathrm{~mm} \mathrm{ACh}$. The reason for this discrepancy is not clearly understood at the present time. This may be partly due to the different preparations employed. In this respect, it is of interest to note that secretion of CA from the cultured cells decreased at higher concentrations of choline (Holz and SENTER, 1981) and furthermore that a similar tendency was observed at higher concentrations of ACh in some experiments (SCHNEIDER et al., 1977; Liang and Perlman, 1979; Kilpatrick et al., 1980).

In addition to its weak nicotinic activation, choline exceeding $130 \mathrm{~mm}$ caused secretion resistant to cholinergic antagonists. Secretion by choline substitution for $\mathrm{Na}$ has been interpreted as being due to $\mathrm{Na}^{+}$deprivation (LASTOWECKA and TRIFARO, 1974; RINK, 1977). This interpretation has to be carefully considered in two respects. Firstly, the secretion observed by them in the absence of nicotinic blocker involves that due to weak nicotinic activation. Secondly, other $\mathrm{Na}^{+}$ substitutes such as $\mathrm{Li}^{+}$and Tris never induced immediate secretion, implying that secretion caused by a high concentration of choline is not simply ascribable to $\mathrm{Na}^{+}$ 
removal. The mechanism of the latter secretion remains to be determined, but our results clearly indicate the necessity of the use of nicotinic blocker for this study.

We wish to thank Dr. T. Gotow (this department) and Mr. K. Fujii, medical student, for their kind and valuable suggestions.

\section{REFERENCES}

Anton, A. H. and SAYre, D. F. (1962) A study of the factors affecting the aluminum oxide trihydroxyindole procedure for analysis of catecholamines. J. Pharmacol. Exp. Ther., 138: 360-375.

Douglas, W. W. and Rubin, R. P. (1961) The role of calcium in the secretory response of the adrenal medulla to acetylcholine. J. Physiol. (Lond.), 159: 40-57.

Douglas, W. W. and RuBIN, R. P. (1963) The mechanism of catecholamine release from the adrenal medulla and the role of calcium in stimulus-secretion coupling. J. Physiol. (Lond.), 167: 288-310.

Fenwick, E. M., Fajdiga, P. B., Howe, N. B. S., and Livett, B. G. (1978) Functional and morphological characterization of isolated bovine adrenal medullary cells. J. Cell. Biol., 76: $12-30$.

Hochman, J. and Perlman, R. L. (1976) Catecholamine secretion by isolated adrenal cells. Biochim. Biophys. Acta, 421: 168-175.

Holz, R. W. and Senter, R. A. (1981) Choline stimulates nicotinic receptors on adrenal medullary chromaffin cells to induce catecholamine secretion. Science, 214: 466-468.

IsHIKAWA, K., HARADA, E., and KANNO, T. (1977) A quantitative analysis of the influence of external calcium and magnesium concentrations on acetylcholine-induced adrenaline release in rat adrenal gland perfused in an antidromic or orthodromic direction. Jpn. J. Physiol., 27: 251-266.

Ito, S., NAKazAto, Y., and OHGA, A. (1980) Exocytotic release of catecholamine from perfused guinea-pig adrenal gland induced by veratridine. Br. J. Pharmacol., 70: 527-535.

KIDOKoRo, Y. and RITCHIE, A. K. (1980) Chromaffin cell action potentials and their possible role in adrenaline secretion from rat adrenal medulla. J. Physiol. (Lond.), 307: 199-216.

Kilpatrick, D. L., Ledbetter, F. H., Carson, K. A., Kirshner, A. G., Slepetis, R., and KIRSHNER, N. (1980) Stability of bovine adrenal medulla cells in culture. J. Neurochem., 35: 679-692.

KIRPeKar, S. M. and Prat, J. C. (1978) Blockade of desensitization of nicotinic receptors of the cat adrenal medulla by concanavalin A. Br. J. Pharmacol., 62: 549-552.

LASTOWECKA, A. and Trifaro, J. M. (1974) The effect of sodium and calcium ions on the release of catecholamines from the adrenal medulla: Sodium deprivation induces release by exocytosis in the absence of extracellular calcium. J. Physiol. (Lond.), 236: 681-705.

LiANG, B. T. and Perlman, R. L. (1979) Catecholamine secretion by hamster adrenal cells. $J$. Neurochem., 32: 927-933.

Molinoff, P. B., Weinshilboum, R., and Axelrod, J. (1971) A sensitive enzymatic assay for dopamine- $\beta$-hydroxylase. J. Pharmacol. Exp. Ther., 178: 425-431.

RINK, T. J. (1977) The influence of sodium on calcium movements and catecholamine release in thin slices of bovine adrenal medulla. J. Physiol. (Lond.), 266: 297-325.

SaAVedra, J. M., Palkovitz, M., Brownstein, M. J., and Axelrod, J. (1974) Localization of phenylethanolamine- $N$-methyl transferase in the rat brain nuclei. Nature (Lond.), 248: 380-386.

SCHNeIDer, A. S., Herz, R., and Rosenheck, K. (1977) Stimulus-secretion coupling in 
chromaffin cells isolated from bovine adrenal medulla. Proc. Natl. Acad. Sci. U.S.A., 74: 5036-5040.

SORIMACHI, M. (1968) Effects of alkali metal and other monovalent ions on the adrenomedullary secretion. Eur. J. Pharmacol., 3: 235-241.

SORIMACHI, M. and YoshidA, K. (1979) Exocytotic release of catecholamine and dopamine- $\beta$ hydroxylase from the perfused adrenal gland of the rabbit and cat. $B r . J$. Pharmacol., 65: 117-125.

Trifaro, J. M. and LeE, R. W. H. (1980) Morphological characteristics and stimulus-secretion coupling in bovine adrenal chromaffin cell cultures. Neuroscience, 5: 1533-1546.

Tsujimoto, A. and Nishikawa, T. (1975) Further evidence for nicotinic and muscarinic receptors and their interaction in dog adrenal medulla. Eur. J. Pharmacol., 34: 327-334.

YoshIZAKI, T. (1973) Participation of muscarinic receptors on splanchnic-adrenal transmission in the rat. Jpn. J. Physiol., 23: 813-816. 